\title{
Factors Affecting the Acceptance and Willingness-to-Pay of End-Users: A Survey Analysis on Automated Vehicles
}

\author{
Xiaobei Jiang ${ }^{1}$, Wenlin $\mathrm{Yu}^{1}$, Wenjie $\mathrm{Li}^{1}{ }^{1}$, Jiawen Guo ${ }^{1}$, Xizheng Chen ${ }^{1}$, Hongwei Guo ${ }^{1}$, Wuhong Wang ${ }^{1}$ \\ and Tao Chen ${ }^{2, *}$ \\ 1 School of Mechanical Engineering, Beijing Institute of Technology, Beijing 100081, China; \\ jiangxiaobei@bit.edu.cn (X.J.); wenlinyu1020@163.com (W.Y.); lwj1783470178@163.com (W.L.); \\ vera987654321@yeah.net (J.G.); xizhengchen@yeah.net (X.C.); guohongwei@bit.edu.cn (H.G.); \\ wangwuhong@bit.edu.cn (W.W.) \\ 2 Key Laboratory of Transportation Industry of Automotive Transportation Safety Enhancement Technology, \\ Chang'an University, Xi'an 710064, China \\ * Correspondence: chentao@chd.edu.cn
}

Citation: Jiang, X.; Yu, W.; Li, W.; Guo, J.; Chen, X.; Guo, H.; Wang, W.; Chen, T. Factors Affecting the Acceptance and Willingness-to-Pay of End-Users: A Survey Analysis on Automated Vehicles. Sustainability 2021, 13, 13272. https://doi.org/ $10.3390 /$ su132313272

Academic Editor: Pan Lu

Received: 4 November 2021

Accepted: 24 November 2021

Published: 30 November 2021

Publisher's Note: MDPI stays neutral with regard to jurisdictional claims in published maps and institutional affiliations.

Copyright: (c) 2021 by the authors. Licensee MDPI, Basel, Switzerland. This article is an open access article distributed under the terms and conditions of the Creative Commons Attribution (CC BY) license (https:// creativecommons.org/licenses/by/ $4.0 /)$.

\begin{abstract}
The emergence of automated vehicles (AVs) is expected to have a huge impact on traffic safety and environmental improvement. In order to promote the sustainable development of $\mathrm{AVs}$, it is urgent to study the public's acceptance of and willingness-to-pay for automated vehicles and their influencing factors. Based on a questionnaire survey and descriptive research, this paper investigates the public's general views on AVs. A psychological model considering technical trust (TT), perceived benefit (PB), perceived risk (PR), and perceived ease of use (PU) was constructed to study the factors that influence the public's acceptance of and willingness-to-pay for AVs. Logistic regression models based on demographic factors such as monthly income (MI) and driving experience (DE) and psychological factors were established to predict end-users' acceptance and willingness-to-pay. The accuracy of the two models is $93.2 \%$ and $87.9 \%$, respectively. Based on the results, the following policies can be put forward to promote the development of AVs: (1) more information to enhance TT; (2) pricing and easy maintenance based on PU; (3) education and training based on TT and PB; and (4) personalized sales based on DE and MI.
\end{abstract}

Keywords: automated vehicles; acceptance; willingness-to-pay; technical trust; perceived benefit; perceived risk; perceived ease of use; monthly income; driving experience

\section{Introduction}

Sustainable transport plays a leading role in economic and social development. Automated vehicles are prime movers in transport development. According to the National Motor Vehicle Crash Causation Survey (NMVCCS), more than $94 \%$ of traffic accidents are caused by human driving errors. The main reasons for driving errors are the driver's limitations and the uncontrollability of information processing [1]. In order to reduce drivers' mistakes and improve road traffic safety, automated driving has become the focus of many researchers [2-5].

An automated vehicle is a vehicle that can sense external stimuli and complete certain specific driving tasks without manual operation [1]. According to the Society of Automotive Engineers (SAE)'s taxonomy for vehicle automation, vehicles with conditional automation (Level 3), high automation (Level 4), and full automation (Level 5) can work in the "selfdriving" ("automated driving") mode.

The emergence of automated vehicles will have a huge impact on society, the economy, and the environment. First, automated vehicles no longer need to be controlled by the driver, avoiding operating errors and, thereby, reducing the occurrence of traffic accidents [6]. Second, automated vehicles are expected to reduce environmental pollution by optimizing the traffic flow and improving fuel economy [6]. Third, automated vehicles 
can be used to reduce users' commuting time, free up users' time in the car, and improve the mobility of some people (the elderly, children, and those without a driver's license) [7]. Finally, automated vehicles may transform car ownership into an on-demand service and shift the design focus of the automotive industry from optimizing the driving experience to enjoying it [8].

However, in the past few years, automated vehicle accidents, including fatal accidents, have been reported. Dozens of news items and studies show that automated vehicles are distrusted by drivers. Users can benefit from AVs depending on their acceptance [9-12]. Some studies have investigated the interaction between drivers and automated vehicles, and the results show that drivers do not fully trust in AVs, and automated driving cannot perfectly replace drivers [13]. Therefore, it is particularly important to study the public's acceptance when introducing new technology into a growing market. The promotion of new technology is a daunting challenge; many products have failed before they are put on the market because they fail to meet the needs of users and are not accepted by users $[14,15]$. The main obstacles to the application of automated vehicles include not only technical problems, but also people's trust and acceptance [16].

Academic and professional researchers, private enterprises, and auto-related websites have conducted surveys to understand public opinions about AV technologies and related aspects. In this study, we performed a detailed literature analysis, focusing on acceptance and willingness-to-pay.

Interviews and questionnaires have been used to study users' acceptance of AVs. Most of the respondents were positive about automated driving [17]. Men are more receptive than women [18]. Research findings show that age, location, and education may influence users' acceptance; a well-educated young man living in an urban area is more willing to accept automated vehicles [19]. The influence of local traffic safety on people's acceptance of automated vehicles has also been investigated [20]. Moreover, an on-road vehicle experiment has been conducted, and the results showed that $64 \%$ of the study's participants had a worse sense of safety in automated buses, especially women [21]. However, the survey was restarted, and the results showed that most of the respondents felt more secure [22]. This shows that advances in technology have made people more willing to accept automated vehicles.

People's willingness-to-pay for automated vehicles is also a research hotspot. Some studies have explored the influence of demographic factors on willingness-to-pay. Significant differences can be found among different countries [10]. Performance expectations, pay expectations, and community have a positive impact on willingness-to-pay [23]. Personal innovation may reinforce this positive influence and persons with more crash experience are more willing to pay for AVs. The public's willingness-to-pay at different automation levels has also been studied. The higher the automation level, the more significant the increase in the respondents' willingness-to-pay. Most respondents are only willing to pay for fully automated vehicles [24,25]. A structural model has been proposed to analyze the influence of psychological factors on willingness-to-pay. Trust and perceived benefit are important and positive factors, while perceived risk is a negative factor [26]. The price of AVs has been found to be a significant factor based on the ordered logit model [27].

Quantitative analysis and model applications of automated vehicles still need more work. In the existing models, the main influencing factors are demographic, psychological, and physiological attributes; for example, unified conclusions have been reached on perception, trust, and country factors. However, an in-depth discussion of travel-related and vehicle-related attributes is still lacking.

In order to determine the key factors affecting users' acceptance of and willingness-topay for automated vehicles, this study used a survey to establish psychological and logical regression models. The results of this work could hopefully provide a theoretical basis for and data support to policy-makers and automobile manufacturers. 


\section{Methodology}

\subsection{Data Collection}

This study focused on highly automated vehicles and used the SP survey method, which is very beneficial for researching respondents' choices and intentions regarding things not currently available.

The questionnaire consists of two parts: (1) respondents' demographic information; and (2) respondents' psychological feelings about AVs. The former includes gender, age, education, income, and driving experience. The latter include technical trust, perceived benefits, perceived ease of use, perceived risk, and travelers' acceptance of and willingnessto-pay for AVs. A Likert scale was used to measure the respondents' understanding of the questions. The options for the income setting were based on China's taxation level. Table 1 shows items and sources related to highly automated vehicles.

Table 1. Variables, content, and sources in the questionnaire.

\begin{tabular}{|c|c|c|c|}
\hline Constructs & Items & Contents & Sources \\
\hline \multirow{2}{*}{ Technical trust } & TT1 & It will be trustworthy & [28] \\
\hline & TT2 & It will be reliable & \\
\hline \multirow{6}{*}{ Perceived benefit } & PB1 & It will reduce the severity of accidents & \\
\hline & PB2 & It will reduce the incidence of traffic accidents & [29] \\
\hline & PB3 & It will reduce travel costs & \\
\hline & PB4 & It will reduce mental and physical fatigue while driving & \\
\hline & PB5 & I will find it useful when I am doing irrelevant things, such as eating & \\
\hline & PB6 & I will find it useful when I am impaired & \\
\hline \multirow{3}{*}{ Perceived ease of use } & PU1 & It will be easily obtained & \\
\hline & PU2 & I will find it easy to use & \\
\hline & PU3 & It will be easy to repair when it fails & \\
\hline \multirow{4}{*}{ Perceived risk } & PR1 & I am worried that there will be equipment or system failures & [29] \\
\hline & PR2 & I am worried that it will leak personal information & \\
\hline & PR3 & I am worried about the legal liability of the driver or owner & \\
\hline & PR4 & I am worried that the cost of it will be too high & \\
\hline \multirow{3}{*}{ Acceptance } & UA1 & I will use and rent it & [28] \\
\hline & UA2 & I will purchase it & [30] \\
\hline & UA3 & I will recommend it to my family and friends & \\
\hline Willingness-to-pay & WP & How much are you willing to spend extra to buy it? (percentage) & [31] \\
\hline
\end{tabular}

\subsection{Survey Participants}

The results of this study come from a questionnaire survey of 294 respondents. The gender, age, education, income, and driving experience of the interviewees were analyzed, and the results are shown in Table 2.

There are slightly more men than women among the respondents, of which men account for $56.12 \%$ and women account for $43.88 \%$. A total of $84.35 \%$ of the respondents are under 40 years old, and the proportion below 30 years old is $53.33 \%$. Most respondents $(91.16 \%)$ have a bachelor's degree or below, while $73.81 \%$ are undergraduates. Respondents with a monthly income of less than 25,000 account for $96.26 \%$, and those with a monthly income of 5000 to 12,000 account for $46.94 \%$. Respondents with 1-5 years of driving experience account for $50.68 \%$.

\subsection{Modeling Framework}

The factors affecting acceptance and willingness-to-pay are technical trust, perceived benefit, perceived risk, and perceived ease of use [32]. In order to better explain the acceptance and willingness-to-pay, a psychological model of AVs was established. The effects of technical trust, perceived benefit, perceived ease of use, and perceived risk on acceptance and willingness-to-pay were studied. Intuitively, for the emerging technology, trust will make people want to use the technology, and a higher perceived benefit and perceived ease of use will also make people more willing to use the technology. At the same 
time, a higher perceived risk will make people not want to use the technology. Figure 1 shows the hypotheses of the psychological model.

Table 2. Summary of demographic and driving experience.

\begin{tabular}{ccc}
\hline & Variable & Percentage \\
\hline \multirow{2}{*}{ Gender } & Male & $56.12 \%$ \\
& Female & $43.88 \%$ \\
Age & $<30$ years old & $53.33 \%$ \\
& $30-40$ years old & $31.02 \%$ \\
& $40-50$ years old & $13.61 \%$ \\
Education & $>50$ years old & $2.04 \%$ \\
& Junior high school & $2.04 \%$ \\
& High school graduate & $15.31 \%$ \\
Monthly income & Bachelor's degree & $73.81 \%$ \\
& Postgraduate degree & $8.84 \%$ \\
& $<5000$ & $25.85 \%$ \\
& $5000-12,000$ & $46.94 \%$ \\
& $12,000-25,000$ & $23.47 \%$ \\
Driving experience & $>25,000$ & $3.74 \%$ \\
& 0 year & $15.31 \%$ \\
& $<1$ year & $17.35 \%$ \\
& $1-3$ years & $27.89 \%$ \\
& $3-5$ years & $22.79 \%$ \\
& $5-10$ years & $11.22 \%$ \\
& $>10$ years & $5.44 \%$ \\
\hline
\end{tabular}

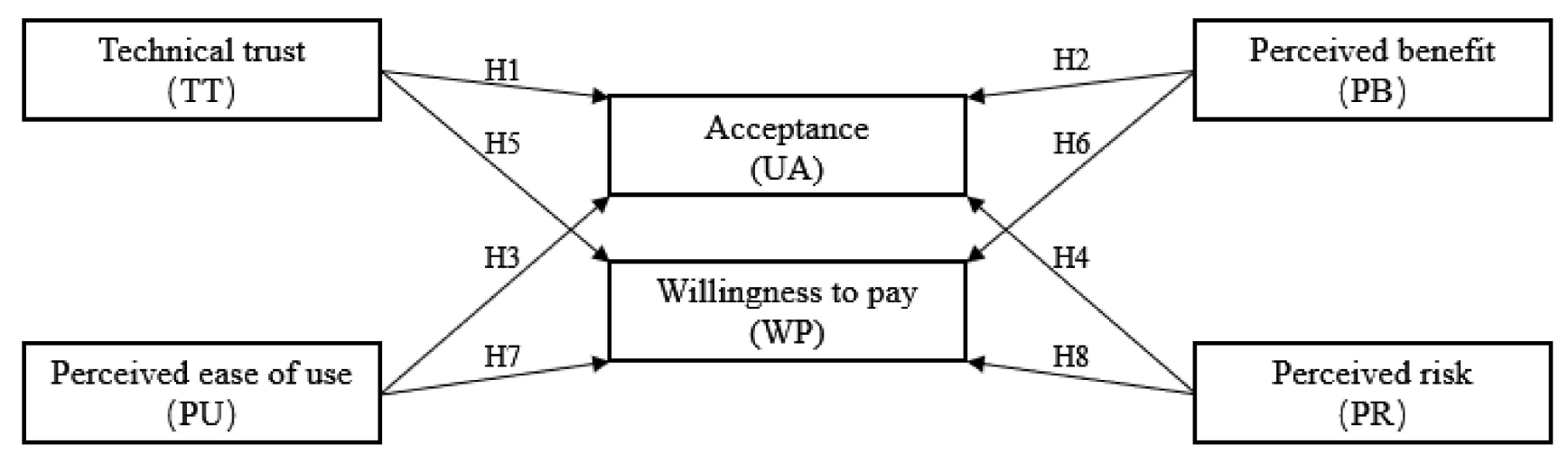

Figure 1. Hypotheses of the psychological model.

\subsection{Data Analysis}

Cronbach's alpha is a measure of the reliability of a scale or test [33]. We used it to analyze the reliability of the questionnaire items. The Cronbach's alpha of perceived ease of use is 0.544 (less than 0.6 ), so the data need to be processed. The CITC indicates the overall correlation of the corrected terms. The CITC of PU2 in perceived ease of use is only 0.282 and has a low correlation with other options, so the reliability analysis was performed again after its deletion.

Table 3 was obtained by eliminating PU2. The Cronbach's alpha of perceived ease of use is 0.546 , but it is only composed of two items, so the reliability is acceptable. After the correction, the reliability of the questionnaire items was found to be acceptable. 
Table 3. Reliability test results.

\begin{tabular}{|c|c|c|c|c|}
\hline Constructs & Items & CITC & $\begin{array}{c}\text { Cronbach's Alpha } \\
\text { (after PU2 Was Deleted) }\end{array}$ & Cronbach's Alpha \\
\hline \multirow{2}{*}{ Technical trust } & TT1 & 0.465 & - & \multirow{2}{*}{0.632} \\
\hline & TT2 & 0.465 & - & \\
\hline \multirow{6}{*}{ Perceived benefit } & PB1 & 0.565 & 0.645 & \multirow{6}{*}{0.715} \\
\hline & PB2 & 0.470 & 0.669 & \\
\hline & PB3 & 0.373 & 0.701 & \\
\hline & PB4 & 0.418 & 0.685 & \\
\hline & PB5 & 0.400 & 0.695 & \\
\hline & PB6 & 0.497 & 0.662 & \\
\hline \multirow{3}{*}{ Perceived ease of use } & PU1 & 0.381 & - & \multirow{3}{*}{0.546} \\
\hline & PU3 & 0.381 & - & \\
\hline & PR1 & 0.483 & 0.550 & \\
\hline \multirow{3}{*}{ Perceived risk } & PR2 & 0.382 & 0.622 & \multirow{3}{*}{0.651} \\
\hline & PR3 & 0.468 & 0.556 & \\
\hline & PR4 & 0.401 & 0.603 & \\
\hline \multirow{3}{*}{ Acceptance } & UA1 & 0.483 & 0.647 & \multirow{3}{*}{0.699} \\
\hline & UA2 & 0.550 & 0.562 & \\
\hline & UA3 & 0.517 & 0.604 & \\
\hline
\end{tabular}

The validity is generally evaluated from two perspectives: (1) the content validity is analyzed from a professional experience perspective; and (2) the structural validity is analyzed from an empirical perspective [34].

The content validity reflects the degree to which the content of the questionnaire fits the research topic, and the expert judgment method is generally used. The questionnaire was judged and revised by professionals, so we determined that the content of the questionnaire was appropriate.

The construct validity is used to test the measurement of variables. Firstly, a KMO test is carried out. If the value is lower than 0.6 and the degree of commonality is lower than 0.4 , the item can be deleted. When there are only two items, the value is always 0.5 . Table 4 shows the conclusions obtained after repeating the above steps until the value reached the target. It can be seen that the common values between the factors are all higher than 0.4 , indicating that the information can be extracted effectively. In addition, the values of multiple variables are all between 0.6 and 0.7 , which means that the data are valid.

Table 4. Validity test results.

\begin{tabular}{cccc}
\hline Constructs & Items & $\begin{array}{c}\text { Common Factor } \\
\text { VARIANCE }\end{array}$ & KMO \\
\hline \multirow{2}{*}{ Technical trust } & TT1 & 0.732 & 0.500 \\
& TT2 & 0.732 & \\
Perceived benefit & PB1 & 0.626 & 0.647 \\
& PB2 & 0.614 & \\
Perceived ease of use & PB6 & 0.524 & 0.500 \\
& PU1 & 0.690 & \\
Perceived risk & PU3 & 0.690 & 0.699 \\
& PR1 & 0.561 & \\
Acceptance & PR2 & 0.414 & 0.667 \\
& PR3 & 0.533 & \\
\hline
\end{tabular}




\section{Results}

\subsection{Descriptive Analysis of the Psychological Model}

Pearson's correlation coefficient was used to measure the vector similarity [35]. First, box plots and scatter plots of the variables were analyzed and outliers were eliminated. Second, the variables were judged on whether they basically conformed to a linear correlation. Then, the normality test was carried out, and the significance of the data was found to be greater than 0.05 . Pearson's correlation analysis was performed after the above conditions were met. The results are shown in Table 5.

Table 5. Pearson's correlation coefficient results.

\begin{tabular}{ccccc}
\hline & TT & PB & PU & PR \\
\hline UA & $+0.747^{* *}$ & $+0.662^{* *}$ & $+0.583^{* *}$ & $-0.269^{* *}$ \\
WP & $+0.376^{* *}$ & $+0.235^{* *}$ & $+0.461^{* *}$ & $-0.183^{* *}$ \\
\hline Notes: $^{* *} p<0.01$. & & & &
\end{tabular}

The respondents' technical trust has a high correlation with acceptance $(\mathrm{H} 1=0.747)$ and shows a positive correlation with willingness-to-pay, but the correlation is relatively weak $(\mathrm{H} 5=0.376)$. Perceived benefit has a high correlation with acceptance $(\mathrm{H} 2=0.662)$ but has a small correlation with willingness-to-pay $(\mathrm{H} 6=0.235)$, so perceived benefit is not a predictor of willingness-to-pay. The respondents' perceived ease of use has a good correlation with acceptance and willingness-to-pay $(\mathrm{H} 3=0.583$ and $\mathrm{H} 7=0.461$, respectively). Perceived risk is negatively correlated with acceptance and willingness-topay, and the correlations are weak ( $\mathrm{H} 4=-0.269$ and $\mathrm{H} 8=-0.183$, respectively). Therefore, perceived risk is not a predictor of the two variables for highly automated vehicles. The above data and the psychological model are shown in Figure 2.

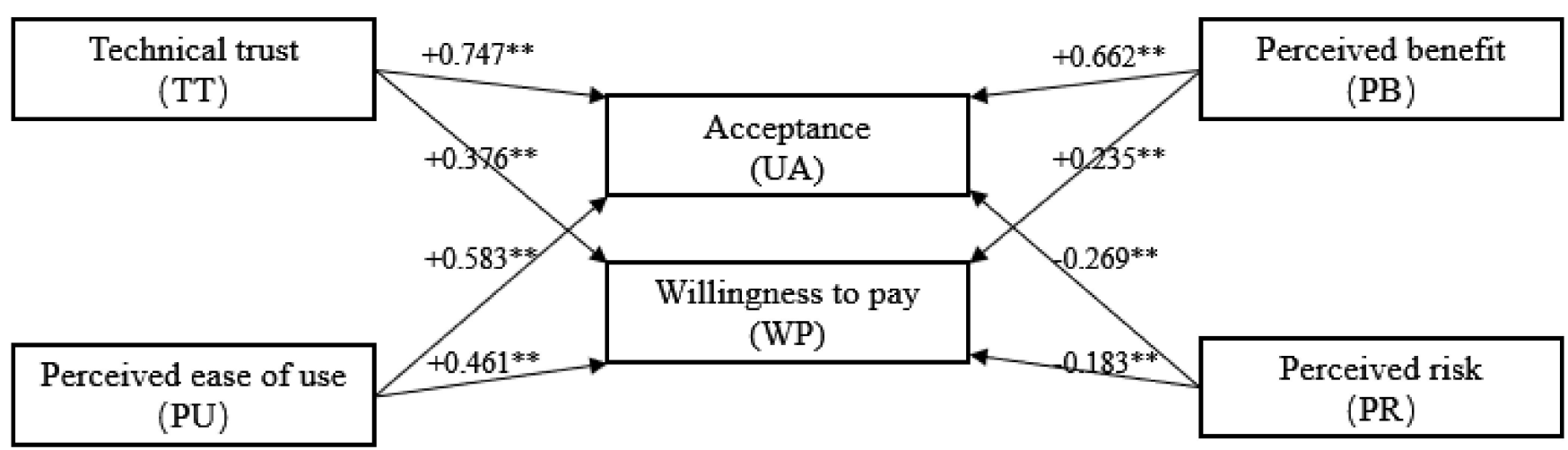

Figure 2. Result of the acceptance and willingness-to-pay psychological model. Notes: ${ }^{* *} p<0.01$.

According to the above correlation analysis, the variables that have a greater impact on acceptance are technical trust, perceived benefit, and perceived ease of use; the variables that have a greater impact on willingness-to-pay are technical trust and perceived ease of use.

\subsection{Descriptive Analysis of Logistic Regression Model}

Many studies have considered the influence of demographic variables on acceptance and willingness-to-pay $[10,29,36]$. Because of the concentrated distribution of age and education, this study only considered the influence of income and driving experience of the respondents. A logistic regression model can be used to understand the relationship between variables [37]. In accordance with the questionnaire, multiple logistic regression models were established to predict acceptance and willingness-to-pay. The variables in the demographic and psychological model were used to propose relevant policies that are needed to promote the use of AVs. 
Because the sample size was not sufficient, the data needed to be processed. The demographic variables include monthly income (MI) and driving experience (DE), and the psychological variables include technical trust (TT), perceived benefit (PB), perceived ease of use (PU), and perceived risk (PR). A total of $80 \%$ of the sample was randomly sampled for modeling, and the remainder was used to verify the accuracy of the model. The results of virtual processing of variables are shown in Tables 6 and 7.

Table 6. Result of virtual processing of independent variables.

\begin{tabular}{ccc}
\hline \multicolumn{2}{c}{ Independent Variables } & Figure \\
\hline \multirow{2}{*}{ Gender } & Male & 0 \\
& Female & 1 \\
& $<5000$ & 0 \\
MI & $5000-12,000$ & 1 \\
& $>12,000$ & 2 \\
& $<1$ year & 0 \\
DE & $1-5$ years & 1 \\
& $>5$ years & 2 \\
TT & $<=5$ & 0 \\
& $>5$ & 1 \\
PB & $<8$ & 0 \\
& $>=8$ & 1 \\
PU & $<=5$ & 0 \\
& $>5$ & 1 \\
PR & $<8$ & 0 \\
& $>=8$ & 1 \\
\hline
\end{tabular}

Table 7. Result of virtual processing of dependent variables.

\begin{tabular}{|c|c|c|}
\hline \multicolumn{2}{|c|}{ Dependent Variable } & \multirow{2}{*}{$\begin{array}{c}\text { Figure } \\
0\end{array}$} \\
\hline & $<8$ & \\
\hline UA & $>=8$ & 1 \\
\hline IID & $<3$ & 0 \\
\hline $\mathrm{WP}$ & $>=3$ & 1 \\
\hline
\end{tabular}

A multiple logistic regression model of acceptance was developed. The processed independent variables and dependent variables were used to train the logistic regression models. We used the forward maximum likelihood estimation method. The "0" group was selected as a reference, and Table 8 shows the acceptance model parameters. P indicates the significance of the variable. OR indicates how many times the number of study subjects is higher than lower. The accuracy of the model is $93.2 \%$.

Table 8. Parameters of the acceptance model.

\begin{tabular}{ccccccc}
\hline Variable & B & S.E & $p$ & OR & \multicolumn{2}{c}{ OR (95\%) } \\
\hline PB & 2.325 & 0.62 & $<0.01$ & 10.222 & 3.033 & 34.448 \\
PU & 1.711 & 0.521 & $<0.01$ & 5.536 & 1.995 & 15.363 \\
TT & 1.85 & 0.963 & $<0.05$ & 6.359 & 0.963 & 42.002 \\
Constant & -2.548 & 1.009 & $<0.05$ & 0.078 & & \\
\hline
\end{tabular}

The variables that affect acceptance in this model are technical trust, perceived benefit, and perceived ease of use. Income, driving experience, and perceived risk were eliminated because they are not significant. The remaining $20 \%$ of the data was used to verify the model. The model has good accuracy $(91.8 \%)$.

This study finds that the regression coefficients of users' technical trust, perceived benefit, and perceived ease of use are positive, which means that they have a significant positive impact on acceptance $(p<0.05)$. The advantages of these three items are great 
$(10.222,5.536$, and 6.359, respectively). Compared with people with lower perceptions (PB, PU, and TT), the acceptance will increase by 10.222, 5.536, and 6.359 times, respectively.

Similarly, a model of willingness-to-pay with an accuracy of $87.9 \%$ was established. The results are shown in Table 9. The variables influencing willingness-to-pay include income, driving experience, technical trust, and perceived ease of use. The remaining data were used to validate the model, and the accuracy was found to be $82.5 \%$.

Table 9. Parameters of the willingness-to-pay model.

\begin{tabular}{ccccccc}
\hline Variable & B & S.E & $p$ & OR & \multicolumn{2}{c}{ OR (95\%) } \\
\hline MI & & & $<0.01$ & & & \\
MI (1) & -1.751 & 0.459 & $<0.01$ & 0.174 & 0.071 & 0.427 \\
MI (2) & -0.28 & 0.402 & 0.486 & 0.756 & 0.343 & 1.662 \\
DE & & & $<0.01$ & & & \\
DE (1) & 1.302 & 0.471 & $<0.01$ & 3.678 & 1.462 & 9.253 \\
DE (2) & 1.35 & 0.401 & $<0.01$ & 3.859 & 1.759 & 8.468 \\
PU & 1.252 & 0.381 & $<0.01$ & 3.497 & 1.659 & 7.372 \\
TT & 1.467 & 0.709 & $<0.05$ & 4.337 & 1.081 & 17.393 \\
Constant & -1.718 & 0.797 & $<0.05$ & 0.179 & & \\
\hline
\end{tabular}

This study finds that the regression coefficients of driving experience, perceived ease of use, and technical trust are positive, which means that they have a significant positive impact $(p<0.05)$. The willingness-to-pay of drivers with $1-5$ years of driving experience is 3.678 times that of trainee drivers ( $<1$ year), and the willingness-to-pay of drivers with more than 5 years of driving experience is 3.859 times that of trainee drivers. As the driving experience increases, the respondents' willingness-to-pay increases significantly. Compared with people with a lower perceived ease of use, the willingness-to-pay will increase by 3.497 times. There are 4.337 times as many respondents who trust technology as respondents who do not trust technology. The variable corresponding to the high-income group is not significant $(p>0.05)$. The regression coefficient of respondents with a monthly income of 5000-12,000 is negative, indicating that income has a significant negative impact on willingness-to-pay $(p<0.01)$.

\section{Discussion}

\subsection{Psychological Factors}

In this study, acceptance and willingness-to-pay were used to measure the public's awareness of automated driving technology. Psychological factors such as technical trust, perceived benefit, perceived risk, and perceived ease of use were used to assess people's acceptance of and willingness-to-pay for automated vehicles. To sum up, there are three findings:

First, technical trust and perceived ease of use play a direct role in the acceptance of and willingness-to-pay for AVs. A study was conducted on American automobile factory employees, and it was found that there is a significant positive correlation between perceived benefit, perceived ease of use, and acceptance [38]. In a word, whether in the psychological model or the logistic regression model, technical trust and perceived ease of use were found to have a direct impact on public acceptance of and willingness-to-pay for AVs. This shows that users are most concerned about the reliability and convenience.

Second, perceived risk has little influence on the two dependent variables. Some studies have put forward evidence to support perceived risk as a negative factor of technology acceptance [39]. However, perceived risk is not a significant factor in people's willingness to use automated vehicles [28]. In this study, the correlation between the respondents' acceptance, willingness-to-pay, and perceived risk is weak. Among the influencing factors, technical trust and perceived ease of use play a greater role than perceived risk. The same conclusion was reached in the logistic regression model. As a result, perceived risk is an unstable predictive variable for AVs. 
Third, perceived benefit is a significant predictor of users' acceptance, not of willingnessto-pay. At present, there is no consistent conclusion in the research on willingness-topay [26]. Some studies show that a higher perceived benefit will lead to a greater willingness to use automated vehicles [40]. In this survey, perceived benefit has a positive impact on acceptance, but the correlation with willingness-to-pay is weak. In the logistic regression model, perceived benefit was not a predictive variable of willingness-to-pay. These results show that a high perceived benefit will encourage users to accept AVs, but the respondents' willingness-to-pay has little to do with perceived benefit, which should be related to other factors such as demographic variables.

\subsection{Logistic Regression Model Factors}

In this paper, logistic multiple regression models with a good degree of fit for acceptance and willingness-to-pay were established. The variables predictive of acceptance are technical trust, perceived benefit, and perceived ease of use. The variables that can predict willingnessto-pay are income, driving experience, technical trust, and perceived ease of use.

Compared with the psychological model, the psychological variables of the two models are highly consistent. Trust and perceived ease of use can be used to predict public acceptance of and willingness-to-pay for advanced automated vehicles. This shows that the respondents have great expectations for the reliability, practicality, and convenience of AVs. Perceived benefit can be used to predict acceptance, which shows that perceived benefit can affect people's acceptance of AVs. There are not only psychological variables but also demographic variables that can predict the willingness-to-pay. People's income and driving experience will affect their willingness-to-pay, which shows that people's willingness-topay is closely related to their own experience. Students in school have lower incomes, and research shows that they are more likely to accept new technologies [32]. In addition, middle-income people may still be skeptical about automated vehicles. Therefore, monthly income is a negative factor. The analysis of driving experience shows that experienced drivers have a deep understanding of the traffic environment that increases their confidence in automated vehicles.

\subsection{Future Research and Limitations}

There are several limitations to the current research on AVs. More respondents are needed in order to increase the accuracy of the model. In this study, most of the respondents were young people. Previous studies have shown that age has no effect on the intention to accept and use AVs [18]. However, the emergence of automated vehicles will change the travel mode of certain groups of people (such as the elderly, children, people without a driver's license, and disabled people). In future research, the potential differences in users' ages need be further considered. In addition, although the data in this paper were collected nationwide, the respondents generally had a higher educational background. Some of the respondents are university students. Because there are systematic differences between students' perception of new technology and the general target population [41], it would be meaningful to study respondents with different educational backgrounds. Finally, cross-cultural research is also needed. Previous studies on the acceptance of AVs show that users in different countries have situational and cultural differences in their perceptions of automated vehicles [24,42]. The acceptance of and willingness-to-pay for AVs of users in different countries need to be analyzed in the future.

\section{Conclusions}

AVs maximize the use of road capacity and prevent accidents caused by human error, such as dangerous driving, fatigue, and drunk driving. AVs play an important role in reducing the urban traffic pressure and the incidence and severity of traffic accidents [43]. People's acceptance of and willingness-to-pay for AVs are the key factors in the popularity of AVs and maintaining the market share. Studying people's acceptance and willingnessto-pay is necessary for the sustainable development of autonomous vehicles. There are 
several considerations that should be put into focus by manufacturers and policy-makers based on several aspects:

First, more information to enhance TT. As automated vehicles become more complex, technical trust has become particularly important. The more people know about the development of automated driving technology, the easier it is for people to trust. Moreover, the perfection of laws related to AVs will also help to enhance users' trust. Through the improvement of automated vehicles, users' technical trust will eventually increase. The higher the technical trust, the higher the users' acceptance and willingness-to-pay.

Second, pricing and easy maintenance based on PU. A reasonable price and a convenient maintenance service will be of benefit to users' acceptance and willingness-to-pay. Reducing the manufacturing cost while retaining quality and car sharing and after sale services will eventually increase the public's perceived ease of use and, thus, users' acceptance and willingness-to-pay.

Thirdly, education and training based on TT and PB. Personal training and feelings will be important factors affecting acceptance and willingness-to-pay. People's opportunities to experience automated technology need to be increased. Automated vehicle test rides and test drive experiences should be continuously provided. These activities can give people a better understanding of what the car is doing and why it is doing it. Through learning, users' awareness of this technology can be improved, and finally technical trust and perceived benefit can be increased.

Fourth, personalized sales based on DE and MI. According to the logistic regression model, driving experience and income will have an impact on willingness-to-pay. Useroriented sales should be the focus of consideration. Based on a standard product or service, a specialized sales solution for an individual can effectively enhance their willingness-to-pay.

Author Contributions: Conceptualization, W.Y. and W.L.; methodology, W.Y. and X.J.; software, W.Y.; validation, X.J.; formal analysis, W.Y., W.L., and J.G.; investigation, X.C. and J.G.; resources, T.C., W.W., and X.J.; data curation, W.Y.; writing—original draft preparation, W.Y.; writing-review and editing, X.J.; visualization, W.Y.; supervision, W.W. and H.G.; project administration, W.W. and H.G.; funding acquisition, T.C., W.W., and X.J. All authors have read and agreed to the published version of the manuscript.

Funding: This work was financially supported by funds of the Key Laboratory of Transportation Industry of Automotive Transportation Safety Enhancement Technology (Chang'an University) (No. 300102221505), the First Batch of 2020 MOE of the PRC Industry-University Collaborative Education Program (No. 202001JG05, the Kingfar-CES “Human Factors and Ergonomics" Program), and the National Natural Science Foundation of China (No. 51805034, 51878045).

Institutional Review Board Statement: Our university does not have an institutional review board for similar research. The study was quite rigorous in guaranteeing the anonymity of participants and emphasizing that data would be used for research purposes only. Before distributing the questionnaire, we obtained informed consent from the participants, informing them that the survey would not have any impact on them. Follow-up research can only be carried out with their permission.

Informed Consent Statement: Informed consent was obtained from all subjects involved in the study.

Data Availability Statement: Data will be made available on reasonable request from the first author.

Conflicts of Interest: The authors declare no conflict of interest.

\section{References}

1. Adnan, N.; Md Nordin, S.; bin Bahruddin, M.A.; Ali, M. How Trust Can Drive Forward the User Acceptance to the Technology? In-Vehicle Technology for Autonomous Vehicle. Transp. Res. Part A Policy Pract. 2018, 118, 819-836. [CrossRef]

2. Becker, F.; Axhausen, K.W. Literature Review on Surveys Investigating the Acceptance of Automated Vehicles. Transportation 2017, 44, 1293-1306. [CrossRef]

3. Deb, S.; Strawderman, L.; Carruth, D.W.; DuBien, J.; Smith, B.; Garrison, T.M. Development and Validation of a Questionnaire to Assess Pedestrian Receptivity toward Fully Autonomous Vehicles. Transp. Res. Part C Emerg. Technol. 2017, 84, 178-195. [CrossRef] 
4. Nordhoff, S.; van Arem, B.; Happee, R. Conceptual Model to Explain, Predict, and Improve User Acceptance of Driverless Podlike Vehicles. Transp. Res. Rec. J. Transp. Res. Board 2016, 2602, 60-67. [CrossRef]

5. Cheng, Q.; Jiang, X.; Zhang, H.; Wang, W.; Sun, C. Data-Driven Detection Methods on Driver's Pedal Action Intensity Using Triboelectric Nano-Generators. Sustainability 2020, 12, 8926. [CrossRef]

6. Fagnant, D.J.; Kockelman, K. Preparing a Nation for Autonomous Vehicles: Opportunities, Barriers and Policy Recommendations. Transp. Res. Policy Pract. 2015, 77, 167-181. [CrossRef]

7. Zhang, T.; Tao, D.; Qu, X.; Zhang, X.; Lin, R.; Zhang, W. The Roles of Initial Trust and Perceived Risk in Public's Acceptance of Automated Vehicles. Transp. Res. Part C Emerg. Technol. 2019, 98, 207-220. [CrossRef]

8. Lam, S.; Taghia, J.; Katupitiya, J. Evaluation of a Transportation System Employing Autonomous Vehicles. J. Adv. Transp. 2016, 50, 2266-2287. [CrossRef]

9. Krueger, R.; Rashidi, T.H.; Rose, J.M. Preferences for Shared Autonomous Vehicles. Transp. Res. Part C Emerg. Technol. 2016, 69, 343-355. [CrossRef]

10. Kyriakidis, M.; Happee, R.; de Winter, J.C.F. Public Opinion on Automated Driving: Results of an International Questionnaire among 5000 Respondents. Transp. Res. Part F Traffic Psychol. Behav. 2015, 32, 127-140. [CrossRef]

11. Lee, Y.-C.; Hand, S.H.; Lilly, H. Are Parents Ready to Use Autonomous Vehicles to Transport Children? Concerns and Safety Features. J. Safety Res. 2020, 72, 287-297. [CrossRef] [PubMed]

12. Zmud, J.; Sener, I.N.; Wagner, J. Self-Driving Vehicles: Determinants of Adoption and Conditions of Usage. Transp. Res. Rec. J. Transp. Res. Board 2016, 2565, 57-64. [CrossRef]

13. Merat, N.; Lee, J.D. Preface to the Special Section on Human Factors and Automation in Vehicles: Designing Highly Automated Vehicles with the Driver in Mind. Hum. Factors J. Hum. Factors Ergon. Soc. 2012, 54, 681-686. [CrossRef]

14. Eichelberger, A.H.; McCartt, A.T. Toyota Drivers' Experiences with Dynamic Radar Cruise Control, Pre-Collision System, and Lane-Keeping Assist. J. Safety Res. 2016, 56, 67-73. [CrossRef]

15. Story, V.; O’Malley, L.; Hart, S. Roles, Role Performance, and Radical Innovation Competences. Ind. Mark. Manag. 2011, 40, 952-966. [CrossRef]

16. Kyriakidis, M.; Sodnik, J.; Stojmenova, K.; Elvarsson, A.B.; Pronello, C.; Thomopoulos, N. The Role of Human Operators in Safety Perception of AV Deployment-Insights from a Large European Survey. Sustainability 2020, 12, 9166. [CrossRef]

17. Nordhoff, S.; de Winter, J.; Kyriakidis, M.; van Arem, B.; Happee, R. Acceptance of Driverless Vehicles: Results from a Large Cross-National Questionnaire Study. J. Adv. Transp. 2018, 2018, 5382192. [CrossRef]

18. Payre, W.; Cestac, J.; Delhomme, P. Intention to Use a Fully Automated Car: Attitudes and a Priori Acceptability. Transp. Res. Part F Traffic Psychol. Behav. 2014, 27, 252-263. [CrossRef]

19. Hudson, J.; Orviska, M.; Hunady, J. People's Attitudes to Autonomous Vehicles. Transp. Res. Policy Pract. 2019, 121, 164-176. [CrossRef]

20. Qu, W.; Xu, J.; Ge, Y.; Sun, X.; Zhang, K. Development and Validation of a Questionnaire to Assess Public Receptivity toward Autonomous Vehicles and Its Relation with the Traffic Safety Climate in China. Accid. Anal. Prev. 2019, 128, 78-86. [CrossRef] [PubMed]

21. Salonen, A.O. Passenger's Subjective Traffic Safety, in-Vehicle Security and Emergency Management in the Driverless Shuttle Bus in Finland. Transp. Policy 2018, 61, 106-110. [CrossRef]

22. Salonen, A.; Haavisto, N. Towards Autonomous Transportation. Passengers' Experiences, Perceptions and Feelings in a Driverless Shuttle Bus in Finland. Sustainability 2019, 11, 588. [CrossRef]

23. Leicht, T.; Chtourou, A.; Ben Youssef, K. Consumer Innovativeness and Intentioned Autonomous Car Adoption. J. High. Technol. Manag. Res. 2018, 29, 1-11. [CrossRef]

24. Bansal, P.; Kockelman, K.M. Forecasting Americans' Long-Term Adoption of Connected and Autonomous Vehicle Technologies. Transp. Res. Part Policy Pract. 2017, 95, 49-63. [CrossRef]

25. Daziano, R.A.; Sarrias, M.; Leard, B. Are Consumers Willing to Pay to Let Cars Drive for Them? Analyzing Response to Autonomous Vehicles. Transp. Res. Part C Emerg. Technol. 2017, 78, 150-164. [CrossRef]

26. Liu, P.; Guo, Q.; Ren, F.; Wang, L.; Xu, Z. Willingness to Pay for Self-Driving Vehicles: Influences of Demographic and Psychological Factors. Transp. Res. Part C Emerg. Technol. 2019, 100, 306-317. [CrossRef]

27. Bansal, P.; Kockelman, K.M. Are We Ready to Embrace Connected and Self-Driving Vehicles? A Case Study of Texans. Transportation 2018, 45, 641-675. [CrossRef]

28. Choi, J.K.; Ji, Y.G. Investigating the Importance of Trust on Adopting an Autonomous Vehicle. Int. J. Hum. Comput. Interact. 2015, 31, 692-702. [CrossRef]

29. Bansal, P.; Kockelman, K.M.; Singh, A. Assessing Public Opinions of and Interest in New Vehicle Technologies: An Austin Perspective. Transp. Res. Part C Emerg. Technol. 2016, 67, 1-14. [CrossRef]

30. Gefen, D.; Karahanna, E.; Straub, D.W. Trust and TAM in Online Shopping: An Integrated Model. MIS Q. 2003, 27, 51. [CrossRef]

31. Gyrd-Hansen, D. Willingness to Pay for a QALY: Theoretical and Methodological Issues. PharmacoEconomics 2005, 23, 423-432. [CrossRef] [PubMed]

32. Xu, Z.; Zhang, K.; Min, H.; Wang, Z.; Zhao, X.; Liu, P. What Drives People to Accept Automated Vehicles? Findings from a Field Experiment. Transp. Res. Part C Emerg. Technol. 2018, 95, 320-334. [CrossRef] 
33. Nadeem, M.; Azam, M.; Asim, M.; Al-Rashid, M.A.; Puan, O.C.; Campisi, T. Does Bus Rapid Transit System (BRTS) Meet the Citizens' Mobility Needs? Evaluating Performance for the Case of Multan, Pakistan. Sustainability 2021, 13, 7314. [CrossRef]

34. Taylan, S.; Özkan, İ.; Çelik, G.K. The Validity and Reliability Analysis of the Turkish Version of the 8-Item Passion Scale. New Ideas Psychol. 2020, 59, 100802. [CrossRef]

35. Ramos, A.G.; Oliveira, J.F.; Gonçalves, J.F.; Lopes, M.P. Dynamic Stability Metrics for the Container Loading Problem. Transp. Res. Part C Emerg. Technol. 2015, 60, 480-497. [CrossRef]

36. Zhang, Q.; Yang, X.J.; Robert, L.P. Drivers' Age and Automated Vehicle Explanations. Sustainability 2021, 13, 1948. [CrossRef]

37. Hardman, S.; Lee, J.H.; Tal, G. How Do Drivers Use Automation? Insights from a Survey of Partially Automated Vehicle Owners in the United States. Transp. Res. Part Policy Pract. 2019, 129, 246-256. [CrossRef]

38. Koul, S.; Eydgahi, A. Utilizing Technology Acceptance Model (TAM) for Driverless Car Technology Adoption. J. Technol. Manag. Innov. 2018, 13, 37-46. [CrossRef]

39. Siegrist, M.; Cousin, M.-E.; Kastenholz, H.; Wiek, A. Public Acceptance of Nanotechnology Foods and Food Packaging: The Influence of Affect and Trust. Appetite 2007, 49, 459-466. [CrossRef] [PubMed]

40. Hohenberger, C.; Spörrle, M.; Welpe, I.M. How and Why Do Men and Women Differ in Their Willingness to Use Automated Cars? The Influence of Emotions across Different Age Groups. Transp. Res. Policy Pract. 2016, 94, 374-385. [CrossRef]

41. Belgiawan, P.F.; Schmöcker, J.-D.; Abou-Zeid, M.; Walker, J.; Lee, T.-C.; Ettema, D.F.; Fujii, S. Car Ownership Motivations among Undergraduate Students in China, Indonesia, Japan, Lebanon, Netherlands, Taiwan, and USA. Transportation 2014, 41, 1227-1244. [CrossRef]

42. Wang, W.; Cheng, Q.; Li, C.; André, D.; Jiang, X. A Cross-Cultural Analysis of Driving Behavior under Critical Situations: A Driving Simulator Study. Transp. Res. Part F Traffic Psychol. Behav. 2019, 62, 483-493. [CrossRef]

43. Dong, X.; DiScenna, M.; Guerra, E. Transit User Perceptions of Driverless Buses. Transportation 2019, 46, 35-50. [CrossRef] 